\title{
Artifacts in MRI: Villain or Hero? Using Artifacts for Diagnosing Central Nervous System Diseases
}

\section{Artefatos em RM: vilões ou heróis? Usando os artefatos para diagnóstico de doenças do sistema nervoso central}

\author{
Gabriela Lopes de Morais ${ }^{1[} \quad$ Gilmar Filho Peruzini $^{11} \quad$ Marcos Rosa-Júnior $^{2}$ \\ ${ }^{1}$ Department of Radiology, Hospital Universitário Cassiano Antônio \\ Moraes, Universidade Federal do Espírito Santo, Vitória, ES, Brazil \\ ${ }^{2}$ Department of Neuroradiology, Hospital Universitário Cassiano Antônio \\ Moraes, Universidade Federal do Espírito Santo, Vitória, ES, Brazil \\ Address for correspondence Marcos Rosa-Júnior, M.D., PhD, Av. Mal. \\ Campos, 1355 - Santa Cecilia, Vitória - ES., Brazil \\ (e-mail: marcosrosajr@hotmail.com). \\ Arq Bras Neurocir 2023;42(1):e8-e13.
}

\begin{abstract}
Keywords

- artifacts

- MRI

- central nervous system

\section{Resumo}

Palavras-chave

- artefatos

- ressonância magnética

- sistema nervoso central

An artifact is a feature present in an image which is not part of the original structure. It can occur as a consequence of several factors. It may be mistaken for pathologic conditions, leading to adverse consequences for the patients. The aim of the present study is to present a selection of the main artifacts described in brain and spinal magnetic resonance images to improve the ability of the physicians to recognize them and to reduce their interference on the final interpretation of a scan. The authors searched the scientific community for artifacts in magnetic resonance imaging (MRI), which were selected to focus on central nervous system (CNS) findings. With the Picture Archiving and Communication System (PACS) database from the center where this study was conducted, the authors designated brain and spine MRI scans with conspicuous artifacts to compose the present study. The artifacts were then classified as those that contribute to the diagnosis and those that must be distinguished from pathologic lesions. Considering the novel classification proposed by the present study, physicians might be stimulated to reevaluate their opinions regarding artifacts, perhaps considering them helpful to evaluate certain conditions even if they cannot be fully corrected, as shown by this distinct approach to artifacts with specific findings concerning differential diagnosis of CNS conditions.

Um artefato está em uma imagem, mas não faz parte da estrutura original. Ele pode ocorrer como consequência de uma miríade de fatores e pode ser confundido com condições patológicas, levando a consequências adversas para os pacientes. O objetivo do presente estudo é apresentar uma seleção dos principais artefatos descritos em imagens de ressonância magnética (RM) cerebral e da coluna vertebral, a fim de melhorar a capacidade dos médicos de reconhecê-los e reduzir sua interferência na interpretação final. Os autores pesquisaram na literatura por artefatos em imagens de
\end{abstract}

received

December 15, 2020

accepted

March 9, 2021
DOI https://doi.org/ $10.1055 / s-0041-1730417$ ISSN $0103-5355$.

\footnotetext{
(C) 2021. Sociedade Brasileira de Neurocirurgia. All rights reserved. This is an open access article published by Thieme under the terms of the Creative Commons Attribution-NonDerivative-NonCommercial-License, permitting copying and reproduction so long as the original work is given appropriate credit. Contents may not be used for commercial purposes, or adapted, remixed, transformed or built upon. (https://creativecommons.org/ licenses/by-nc-nd/4.0/)

Thieme Revinter Publicações Ltda., Rua do Matoso 170, Rio de Janeiro, RJ, CEP 20270-135, Brazil
} 
RM, os quais foram selecionados para se concentrar nos achados do sistema nervoso central (SNC). Com o banco de dados Picture Archiving and Communication System (PACS) do centro onde o presente estudo foi realizado, os autores separaram exames de RM do cérebro e da coluna com artefatos conspícuos para compor o presente estudo. Os artefatos foram então classificados como aqueles que contribuem para o diagnóstico e os que devem ser diferenciados de lesões patológicas. Considerando esta classificação proposta, os médicos podem ser estimulados a reavaliar suas opiniões a partir de artefatos, e estes podem ser úteis para avaliar certas condições, mesmo que não possam ser totalmente corrigidas, como mostrado por esta abordagem distinta para artefatos com achados específicos relativos ao diagnóstico diferencial de condições do SNC.

\section{Introduction}

Magnetic resonance imaging (MRI) is the modality of choice to evaluate central nervous system (CNS) parenchyma. Due to the complex technology involved in generating the scans, artifacts are prone to occur. ${ }^{1-3}$

An artifact is a feature present in an image that is not part of the original structure. It is a consequence of hardware/ software failures; physiologic motion, as cerebrospinal fluid (CSF) flow; or ferromagnetic objects within the patient, like neurosurgical clips. ${ }^{2,4}$

Comprehending artifacts is challenging: multiple authors $^{3,5-7}$ have demonstrated that the physical principles related to their occurrence should be minimally understood to minimize the emergence of artifacts, as misunderstanding an artifact as a disease may have adverse consequences for the patient. ${ }^{4}$

Therefore, beyond discerning basic physics interactions that merge into an artifact, the present study illustrates that recognition of an artifact itself is useful to recall true pathologies and often aids in differential diagnosis of CNS diseases. Thus, although artifacts usually impair the information contained in the image, we demonstrate that, in some cases, it can be used as a tool to help in differential diagnosis.

\section{Materials and Methods}

This is a retrospective study that summarizes the artifacts found in brain and spine MRI. After approval by the institutional review board and by the local ethics committee, artifacts were listed and narrowed down to focus on CNS findings. According to the findings, we analyzed them as artifacts that contribute to diagnosis and artifacts similar to pathologic lesions.

The images were evaluated and selected by an experienced neuroradiologist (10 years of experience).

The authors selected 10 artifacts among their research, considering 5 that contribute to diagnosis and 5 similar to pathologic findings.

The classification proposed by the present study aims to instigate physicians to consider artifacts as findings that, apart from disturbing the original object, are helpful to evaluate certain conditions even if they cannot be fully corrected.

\section{Results and Discussion}

\section{Artifacts Contributing to Diagnosis}

This section includes findings that, due to the nature of their occurrence, might aid physicians diagnosing certain conditions.

Chemical Shift Artifact: The different frequency of resonance between fat and water generates an artifact presented as bright and dark lines along the interface of water and lipids ${ }^{1-5}$ (-Fig. 1). Commonly, it shows up in organs filled with fluids, 2,3 but it can also appear in brain MRI and it is simple to detect. The presence of fat within lesions can generate this artifact, which may point, for instance, extravisceral extension of peripheral tumors. ${ }^{2}$ When exhibited as a dark line, it is called black boundary artifact, or chemical shift type $2^{1,3}$ (-Fig. 1A).

Its correction relies on adjustments of imaging acquisition parameters, like switching phase- and frequency-encoding directions; increasing receiver bandwidth; and applying fat suppression. $^{3-6}$

Flow Artifact: Both CSF and blood flow artifacts are physiologic phenomena that may interfere with image acquisition during an MRI scan.

Cerebrospinal fluid flow artifacts relates to pulsation of CSF during sequence acquisition, ${ }^{1,4}$ which usually presents as ghosting ${ }^{3,4}$ (-Fig. 2A). Its presence indicates adequate or increased CSF flow; its absence, however, may indicate

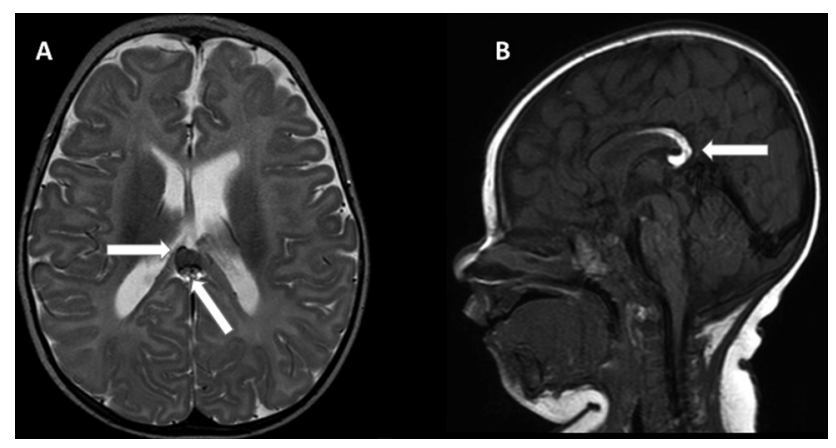

Fig. 1 Chemical shift artifact emphasizes a pericallosal lipoma. The chemical shift artifact suggests the diagnosis of a fat-containing lesion: Black boundary (A - axial T2WI) and chemical shift (B - sagittal T1WI), variations of the same artifact, highlight and delimit the contours of the lesion, thus reinforcing the hypothesis of a lipoma. 


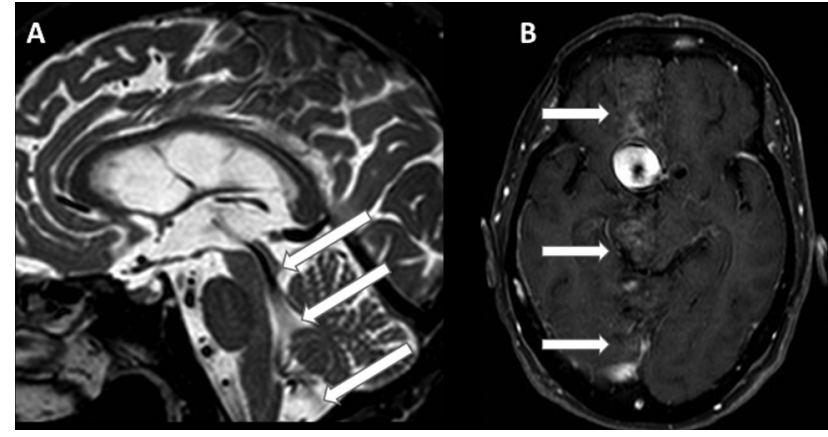

Fig. 2 Flow artifact identifying normal pressure hydrocephalus and an anterior circulation aneurysm. A - Sagittal T2W scan with increased CSF flow due to NPH, generating an artifact (arrows). The increased velocity and turbulent flow within the distended aqueduct of Sylvius generates a signal void that is represented by the flow artifact, generating the trumpet sign. Such finding may corroborate the presence of hydrocephalus. B - Axial T1W scan illustrating a giant aneurysm with an artifact due to turbulent blood flow (arrows). This artifact reinforces distinction between aneurysms and neoplastic/ infectious lesions, as it is augmented by the vessel itself. A solid or solid-cystic lesion would not cause such interference.

decreased flow due to a structural abnormality of the spinal cord (-Fig. 3).

Likewise, the use of intravenous gadolinium may improve blood flow artifacts due to brighter blood signals. ${ }^{7}$ However, such artifacts may be useful to distinguish solid lesions from cysts or aneurysms (-Fig. 2B).

Gradient moment nulling or application of saturation bands $^{3,4}$ are ways to reduce these artifacts. Besides, Li et al ${ }^{7}$ have shown that a spiral spin-echo acquisition sequence was more efficient in reducing flow artifacts than the usually applied cartesian turbo spin-echo sequences. Therefore, it improves image quality, revealing even more subtle changes that were previously obscured.

\section{Artifacts Similar to Central Nervous System Pathologies}

This section includes artifacts that, if wrongly evaluated, may be confounded with organic diseases. However, some findings may help to distinguish artifacts from true pathologic lesions.

Entry slice artifact: this artifact correlates with the thickness of the slice and excitation of blood vessels. ${ }^{1}$ If the slices are too thick, the spins of some vessels may be saturated by earlier excitation pulses that were directed to other slices. Then, the blood vessel acquires a bright, punctual signal in the first slice in which it appears. ${ }^{8}$

This artifact could be mistaken for venous thrombosis or ruptured dermoid cyst (-Fig. 4), which could lead to an important misdiagnosis that would have serious consequences for the patient.

To remove this artifact, the main tactics are placement of partial saturation bands before the first slice and after the last one; and gradient echo flow techniques. ${ }^{8}$

Cerebrospinal fluid flow artifact: cerebrospinal fluid flow may disturb the original signal and cause distortions that resemble diseases such as dural fistulae (-Fig. 5). A dural fistula is an arteriovenous shunt between the dural arterial supply of the nerve root and the underlying medullary vein ${ }^{8}$ that appear as perimedullary dilations.

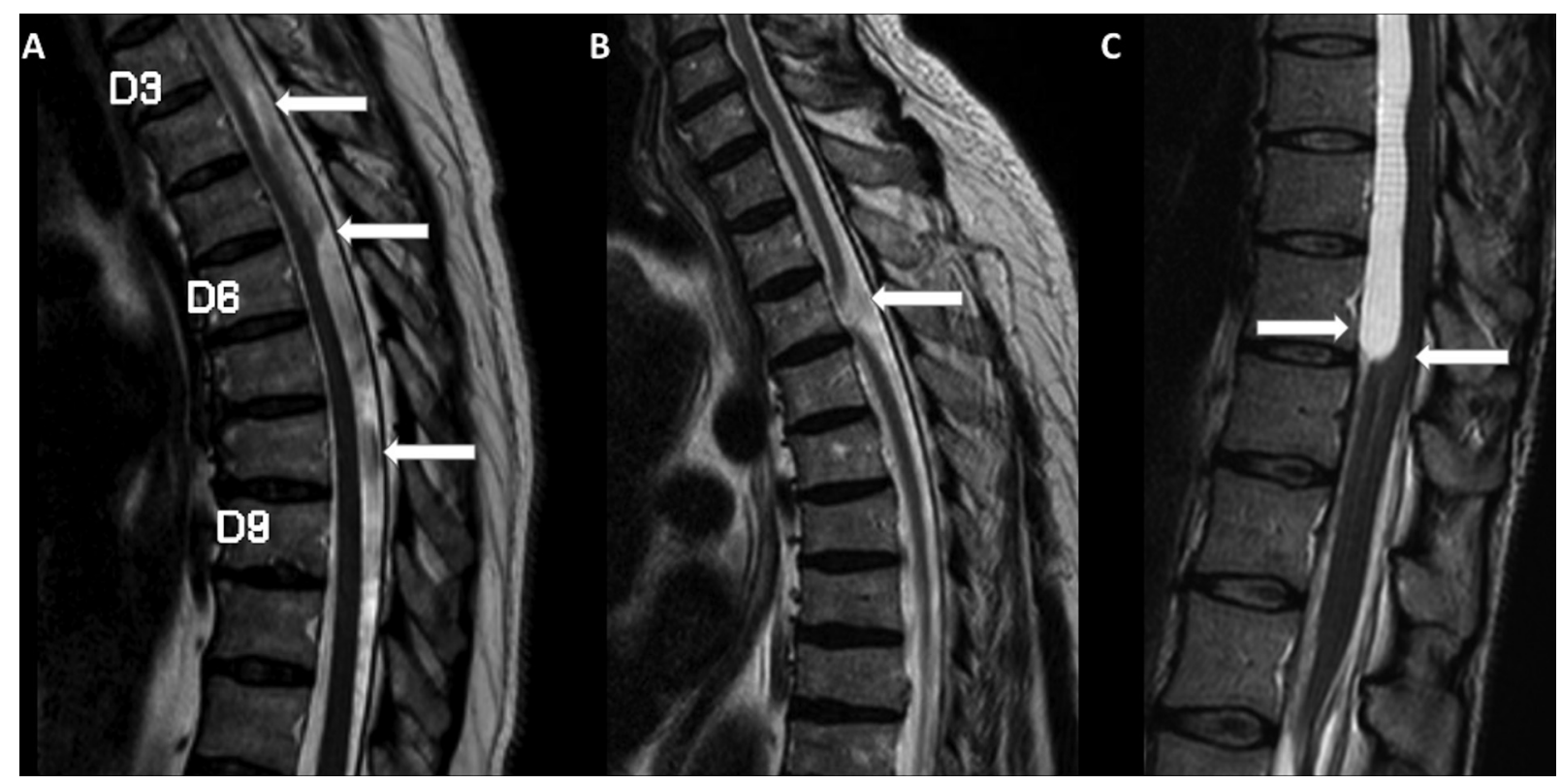

Fig. 3 Absence of CSF flow artifact and intradural cist. A - Sagittal T2WI illustrating a case of thoracic arachnoid web, which is a thick band of arachnoid tissue in the dorsal aspect of the spinal cord that distorts and pushes the cord anteriorly. Consequently, there is widening of the posterior liquoric column, resembling the shape of a surgical scalpel, hence the term "scalpel sign". B - Sagittal T2WI depicting a patient with ventral cord herniation. Note the focal distortion and rotation of the cord, which is protruding anteriorly through a dural defect, with consequent obliteration of the anterior liquoric space. In both scans, we can observe the habitual CSF flow artifact (arrows) in the posterior CSF spaces, since there is no obstruction to the flow in these compartments. The absence of the artifact, as seen on C, suggests, on the other hand, the presence of a condition that causes obstruction to the liquoric flow, represented in this case by a large T2-hyperintense cyst in the anterior aspect of the thoracic spine canal. 


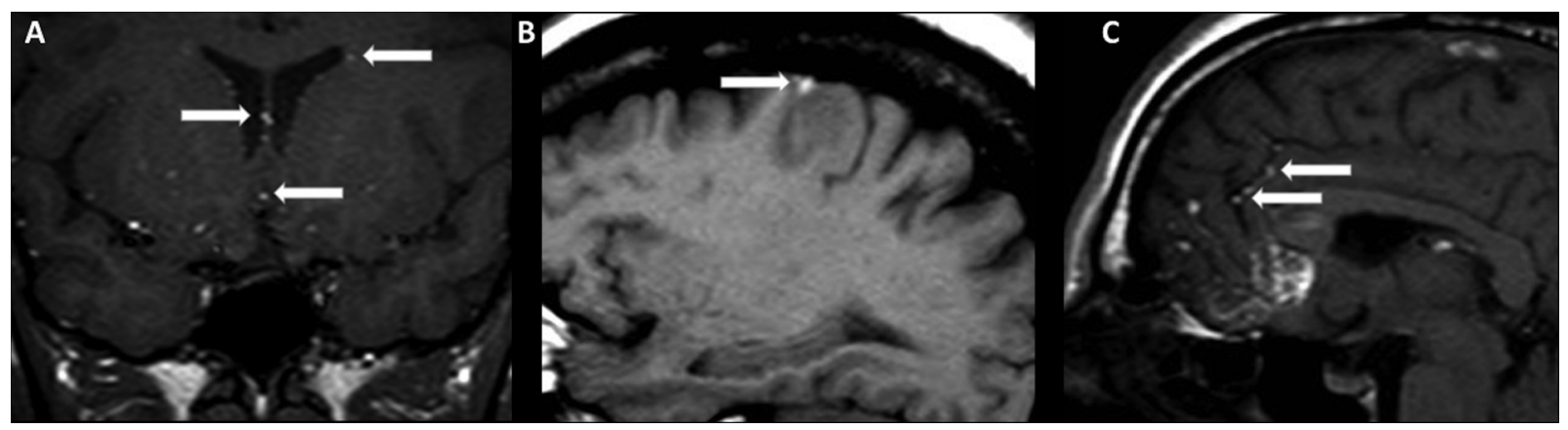

Fig. 4 Entry-slice artifact (A) should not be confused with venous thrombosis (B) or ruptured dermoid cyst (C). A careful look into the complete scan on the left shows this is the only slice in which the bright spot shows up, and, therefore, it is an artifact. It must be distinguished from a true cortical vein thrombosis: the scan must have multiple slices in which the bright spot appears, and, besides, it has to respect the CNS vascular anatomy. On C, it is possible to see the dermoid cyst inferiorly at the base of the frontal lobe and the fat in the subarachnoid space.

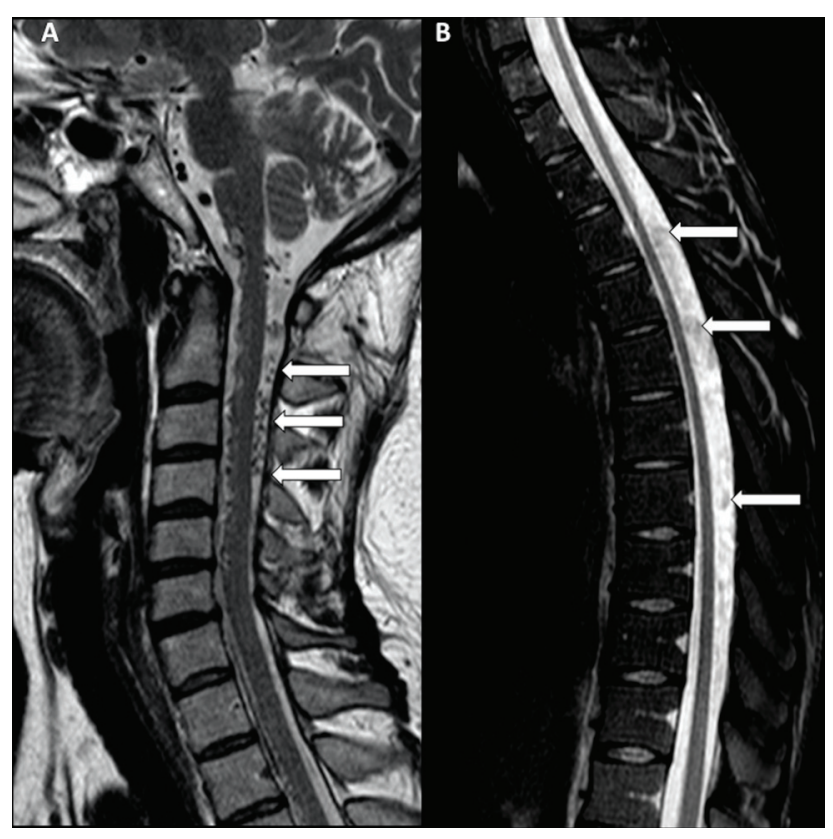

Fig. 5 CSF flow simulating a dural fistula. A - Sagittal T2WI illustrating a dural fistula, with prominent and dilated intradural vessels; B - Sagittal T2WI scan and CSF flow artifact around the spinal cord. For unsuspecting physicians, the alterations may resemble a dural fistula.
It may be distinguished from the artifact by a salt-andpepper appearance in postcontrast images ( $\mathbf{F i g}$. 5A). Even so, it can be challenging to differentiate such findings.

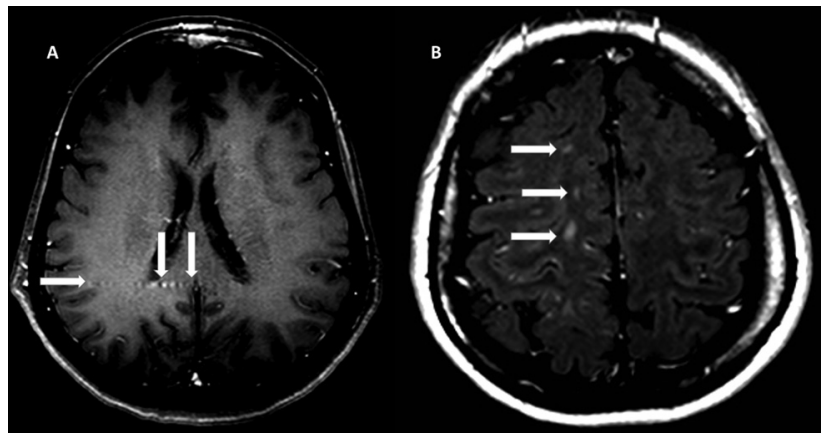

Fig. 7 Blood-flow artifact versus demyelinating focus in a patient with multiple sclerosis (MS). Axial T1WI scan with an enlarged subcutaneous vessel mimicking enhancement foci within the white matter (arrows; A) approaching the midline. Note that the artifact was generated respecting a linear horizontal pattern; Axial T1WI postcontrast of a patient with MS, where the demyelinating areas (arrows; B) present vertically, not as regular as the artifact, and respecting the right brain hemisphere.

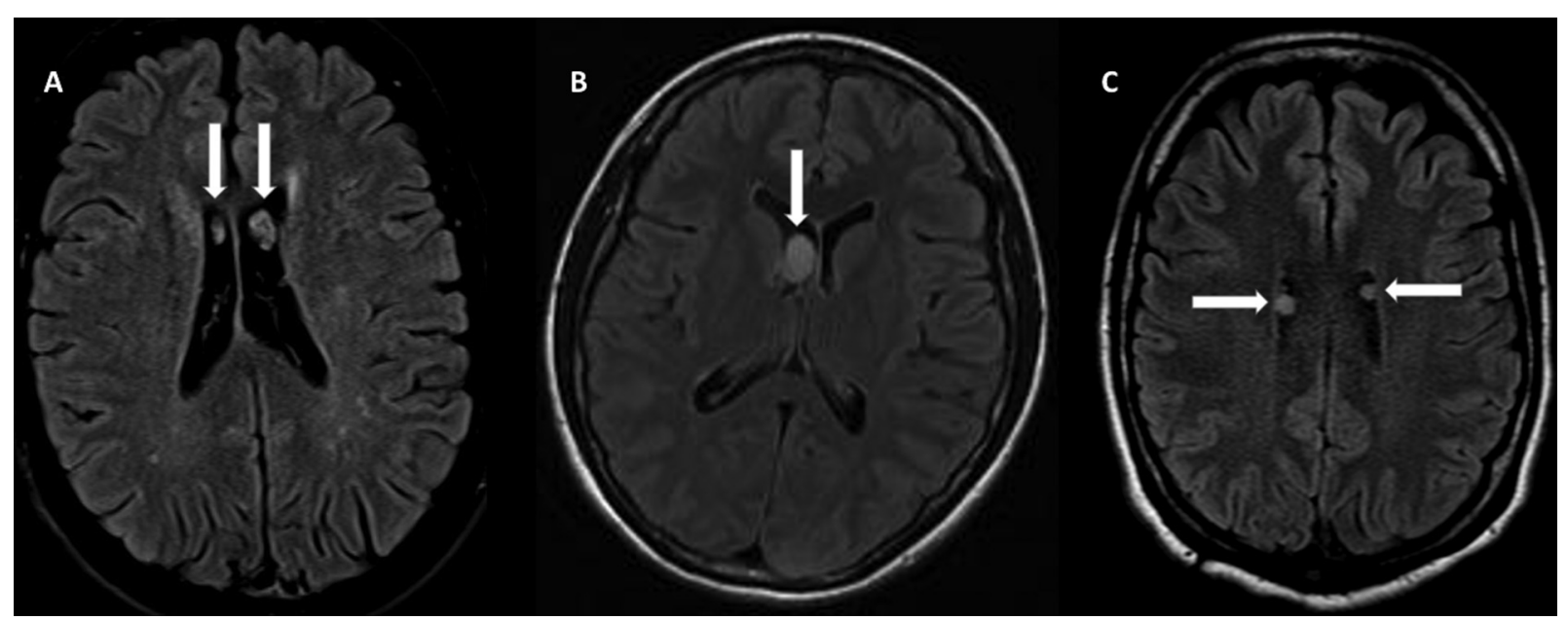

Fig. 6 Axial FLAIR scan with CSF pulsation artifact and its differential diagnosis. CSF flow artifact on the lateral ventricles (arrows; A), mimicking subependymal nodules (B) or ring-shaped lateral ventricular nodules (C). B - Patient with tuberous sclerosis and subependymal giant cell astrocytoma (SEGA; arrow). Size of the lesion, postcontrast enhancement and growth suggest that a subependymal nodule in a patient with tuberous sclerosis might have developed a subjacent SEGA. 


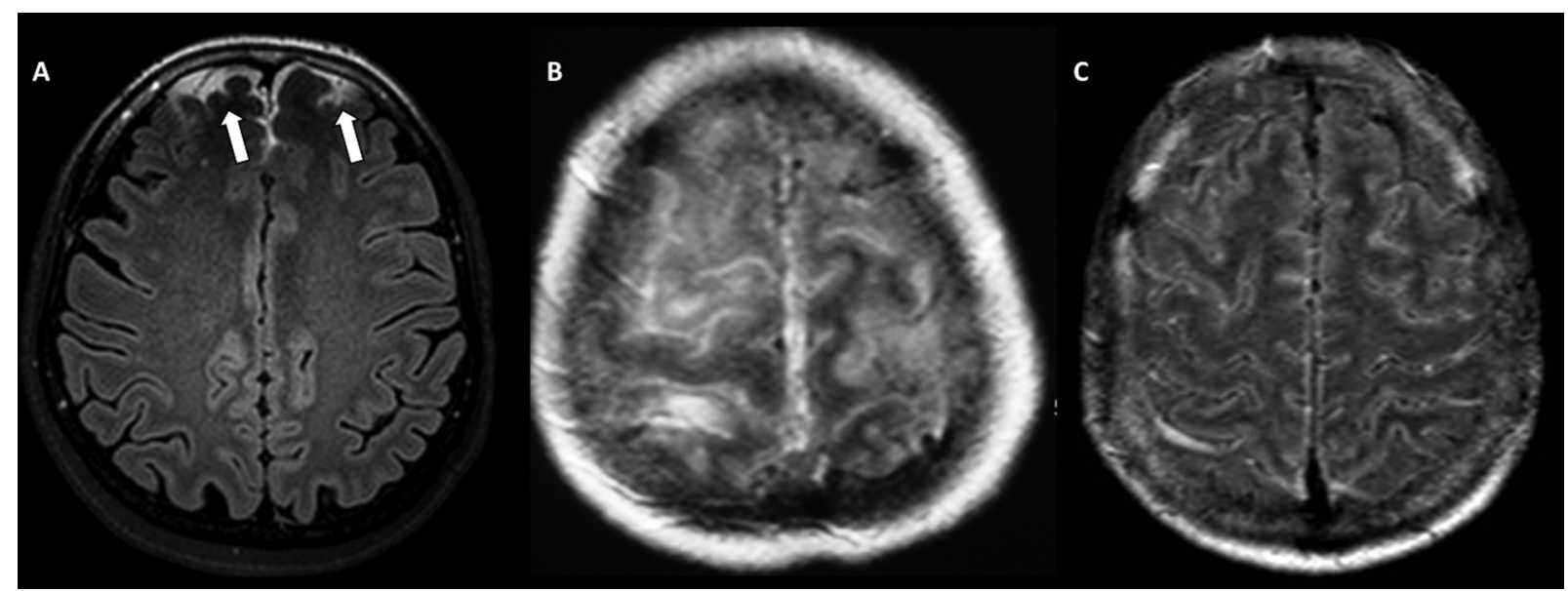

Fig. 8 Susceptibility artifact as hyperintense signal within the subarachnoid space. Susceptibility artifact in this case is a hyperintensity focused on the frontal lobes in an axial FLAIR scan (A), mimicking subarachnoid hemorrhage (B) or meningitis (C). Subarachnoid hemorrhage presents as a diffuse hyperintense signal filling the sulci and with blurrier limits. In both cases, the clinical features add a great deal to the differential diagnosis, as well as lumbar puncture findings.

Clinical correlation is essential, and spinal angiography may be considered in complex cases.

Cerebrospinal fluid flow may also present as nodullary figures within the ventricles, requiring differential diagnosis with tuberous sclerosis and ring-shaped lateral ventricular nodes $^{9,10}$ (-Fig. 6). To distinguish these entities from an artifact, clinical findings, past history and repetition of the scan are useful tools.

Blood-flow artifact: as described above, blood rushing through vessels might generate artifacts. Here, we illustrate an artifact mimicking multiple sclerosis active lesions (-Fig. 7).

Susceptibility artifact: the nonuniformity of the magnetic field is caused by the imaged object, either as a consequence of different magnetic susceptibilities of distinct tissues ${ }^{1,3-5}$ or due to the presence of ferromagnetic objects within the body, such as dental braces. ${ }^{2,3}$ Consequently, such artifacts correlate directly with the shape, size and amount of metal of the implant. It presents as signal loss and field distortion ${ }^{1,3-5}$ (-Fig. 8).

\section{Conclusions}

As unwanted features that may show up in an MRI scan, artifacts may interfere negatively in the interpretation of an image. Nevertheless, some characteristics may contribute to the differential diagnosis of specific conditions. In this context, certain artifacts are expected to be routinely found in MRI studies, since some of them arise from physiologic phenomena within the body. Therefore, not only the presence of artifacts, but also their absence, may indicate an underlying pathology.

We have compiled, in a simple lexicon, a new perspective regarding the most common artifacts in CNS MRI scans, as some may help in the differential diagnosis of neurologic conditions and some resources present so far to improve image quality.

As MRI advances, new sequences arise and, alongside them, a variety of artifacts. Therefore, constant studying of these findings is necessary to improve the diagnostic ability to the most.

\section{Ethical Approval}

This study was approved by the local ethics committee. All procedures performed in studies involving human participants were in accordance with the ethical standards of the institutional and/or national research committee and with the 1964 Helsinki declaration and its later amendments or comparable ethical standards.

\section{Informed Consent}

For this type of study, formal consent is not required.

\section{Author Contribution List}

All authors contributed to the study conception and design. Material preparation, data collection and analysis were performed by Morais G. L. and Filho G. P. The first draft of the manuscript was written by Morais G. L., and all authors commented on previous versions of the manuscript. All authors read and approved the final manuscript.

\section{Funding}

Gabriela L. de Morais was supported by the National Council for Scientific and Technological Development (CNPq, in the Portuguese acronym), and Marcos RosaJúnior was supported by the Fundação de Amparo à Pesquisa e Inovação do Espírito Santo - FAPES.

Conflict of Interests

The authors have no conflict of interests to declare.

\section{References}

1 Somasundaram K, Kalavathi P. Analysis of imaging artifacts in MR brain images. Orient J Comp Sci \& Technol. 2012;5:135-141

2 Krupa K, Bekiesińska-Figatowska M. Artifacts in magnetic resonance imaging. Pol J Radiol 2015;80:93-106 
3 Huang SY, Seethamraju RT, Patel P, Hahn PF, Kirsch JE, Guimaraes AR. Body MR Imaging: Artifacts, k-Space, and Solutions. Radiographics 2015;35(05):1439-1460

4 Ogbole G, Odo J, Efidi R, Olatunji R, Ogunseyinde A. Brain and spine imaging artefacts on low-field magnetic resonance imaging: Spectrum of findings in a Nigerian Tertiary Hospital. Niger Postgrad Med J 2017;24(02):97-102

5 Triche BL, Nelson JT Jr, McGill NS, et al. Recognizing and Minimizing Artifacts at CT, MRI, US, and Molecular Imaging. Radiographics 2019;39(04):1017-1018

6 Heilend S. From A as in Aliasing to $\mathrm{Z}$ as in Zipper: Artifacts in MRI. Clin Neuroradiol 2008;18:25-36
7 Li Z, Hu HH, Miller JH, et al. A Spiral Spin-Echo MR Imaging Technique for Improved Flow Artifact Suppression in T1-Weighted Postcontrast Brain Imaging: A Comparison with Cartesian Turbo Spin-Echo. AJNR Am J Neuroradiol 2016;37(04):642-647

8 Atlas SW. Magnetic Resonance Imaging of the Brain and Spine, $4^{\text {th }}$ edition. Philadelphia: Lippincott Williams \& Wilkins; 2009

9 Rosa Júnior M, Vieira VLF. Ring-shaped lateral ventricular nodules: a "leave me alone" lesion. Arq Neuropsiquiatr 2018;76(07): 494

10 Krishnan A, Kaza RK, Vummidi DR. Cross-sectional Imaging Review of Tuberous Sclerosis. Radiol Clin North Am 2016;54 (03):423-440 